\title{
Reciprocal modulation of adult beta cell maturity by activin $A$ and follistatin
}

\author{
M. Szabat • J. D. Johnson • J. M. Piret
}

Received: 31 January 2010 /Accepted: 22 March 2010 /Published online: 4 May 2010

(C) Springer-Verlag 2010

\begin{abstract}
Aims/hypothesis The functional maturity of pancreatic beta cells is impaired in diabetes mellitus. We sought to define factors that can influence adult beta cell maturation status and function.

Methods MIN6 cells labelled with a $P d x 1$ monomeric red fluorescent protein-Ins 1 enhanced green fluorescent protein dual reporter lentivirus were used to screen candidate growth and/or differentiation factors using image-based approaches with confirmation by real-time RT-PCR and assays of beta cell function using primary mouse islets.
\end{abstract}

Electronic supplementary material The online version of this article (doi:10.1007/s00125-010-1758-0) contains supplementary material, which is available to authorised users.

M. Szabat · J. M. Piret

Michael Smith Laboratories, University of British Columbia,

Vancouver, BC, Canada

M. Szabat

Genetics Graduate Program, University of British Columbia,

Vancouver, BC, Canada

J. D. Johnson $(\bowtie)$

Department of Cellular and Physiological Sciences,

University of British Columbia,

5358 Life Sciences Building, 2350 Health Sciences Mall,

Vancouver, BC, Canada V6T 1Z3

e-mail: jimjohn@interchange.ubc.ca

J. D. Johnson

Department of Surgery, University of British Columbia,

Vancouver, BC, Canada

J. M. Piret

Department of Chemical and Biological Engineering,

University of British Columbia,

Vancouver, BC, Canada
Results Activin A strikingly decreased the number of mature beta cells and increased the number of immature beta cells. While activins are critical for pancreatic morphogenesis, their role in adult beta cells remains controversial. In primary islets and MIN6 cells, activin A significantly decreased the expression of insulin and several genes associated with beta cell maturity (e.g. $P d x 1, M a f a$, Glut2 [also known as Slc2a2]). Genes found in immature beta cells (e.g. Mafb) tended to be upregulated by activin A. Insulin secretion was also reduced by activin A. In addition, activin A-treated MIN6 cells proliferated faster than non-treated cells. The effects of endogenous activin A on beta cells were completely reversed by exogenous follistatin.

Conclusions/interpretation These results suggest that autocrine and/or paracrine activin A signalling exerts a suppressive effect on adult beta cell maturation and function. Thus, the maturation state of adult beta cells can be modulated by external factors in culture. Interventions inhibiting activin or its signalling pathways may improve beta cell function. Understanding of maturation and plasticity of adult pancreatic tissue has significant implications for islet regeneration and for in vitro generation of functional beta cells.

Keywords Beta cells · Gene expression · Human and mouse islets · Insulin · Differentiation - MIN6 · PDX1 . Reporter lentivirus

$\begin{array}{ll}\text { Abbreviations } \\ \text { BMP } & \text { Bone morphogenetic protein } \\ \text { eGFP } & \text { Enhanced green fluorescent protein } \\ \text { mRFP } & \text { Monomeric red fluorescent protein } \\ \text { NEUROG3 } & \text { Neurogenin } 3\end{array}$




\section{Introduction}

The loss of functional pancreatic beta cell mass is a hallmark of diabetes. A fundamental understanding of pancreatic beta cell fate decisions and the process of beta cell maturation is imperative to correct this defect. Using a dual reporter lentiviral system to perform single-cell analysis of beta cell differentiation, we recently characterised a dynamic immature beta cell state in adult islet cells from humans and mice, distinguished by $P d x 1$ promoter activity prior to $I n s 1$ promoter activity $\left(\mathrm{Pdx}^{+} / \mathrm{Ins}^{\text {low }}\right)[1]$. MIN6 beta cell maturation is marked by the acquisition of Ins 1 promoter activity and takes less than $12 \mathrm{~h}$ [1].

Functional beta cell mass can adapt to changes in metabolic demand resulting from obesity or pregnancy [2], suggesting that physiological and pathophysiological factors modulate the differentiation status of adult beta cells. In vitro and in vivo, pancreatic beta cells have also been stimulated to proliferate, dedifferentiate and transdifferentiate [3-5]. The plasticity of adult human pancreatic tissue has significant implications for islet regeneration and for in vitro generation of functional beta cells. However, the specific conditions and molecular cues that drive these mechanisms remain to be elucidated.

Here, our aim was to define factors that modulate the maturation state of adult beta cells. Factorial design of experiments [6] was used to compare multiple candidate growth and differentiation factors simultaneously. Based on factors reported to influence the development or differentiation of beta cells, we examined the effects of glucose [7], nicotinamide [8], exendin 4 [9], insulin [10, 11], IGF-1 [12], betacellulin [12], laminin-1 [13], epidermal growth factor [14], retinoic acid [15], gastrin17 [14], hepatocyte growth factor [16] and activin A [17]. To date, the effects of these factors and their interactions have not been systematically compared in one study.

Activins, members of the TGF $\beta$ superfamily, elicit numerous context-dependent effects on growth and differentiation [18]. Activins control embryonic patterning of foregut-derived organs [19], have important roles in pancreatic development [20] and have been implicated in the control of insulin secretion [21, 22]. Activins and their receptors are present in the developing pancreas and adult islet cells [23, 24]. Follistatin, a potent endogenous activin antagonist, is also produced in adult islets [23, 24]. These observations suggest that activins may play dynamic, tightly controlled autocrine and/or paracrine roles in adult islets. Here, using a novel image-based screening approach, activin A was found to dedifferentiate mature beta cells. Activin A decreased expression of the insulin gene and other mature beta cell genes, while increasing beta cell proliferation. These effects were fully reversed by follistatin, which augmented the mature beta cell phenotype. Our data point to a powerful local regulatory system within islets, which controls the maturity of adult beta cells.

\section{Methods}

Cell culture Human islets were kindly provided by G. Warnock and the Ike Barber Human Islet Transplant Laboratory (Vancouver General Hospital, Vancouver, BC, Canada) and cultured as described [11]. Mouse islets were isolated from 10to 12-week-old C57BL/6J mice as described [25] and cultured overnight in RPMI 1640 with 10\% (vol./vol.) FBS. MIN6 cells were cultured as described [1]. Activin A and follistatin were purchased from R\&D Systems (Minneapolis, MN, USA). All doses of activin A used in this study were at a saturating level (Electronic supplementary material [ESM] Fig. 1). Culture reagents were from Invitrogen (Burlington, ON, Canada), unless otherwise stated. Animal and human cell protocols were approved by the University of British Columbia, Canada in accordance with national guidelines.

Lentiviral vector production and infection The dual reporter pTiger $P d x 1$ monomeric red fluorescent protein (mRFP)Ins 1 enhanced green fluorescent protein (eGFP) and control pTigerCMVeGFP and pTigerInsleGFP lentiviral vectors were used to label MIN6 cells; details on vector construction, virus generation, infection protocols and expression validation have been described elsewhere [1]. Briefly, MIN6 cells were seeded in six-well plates the day before infection. Lentiviral vectors were added at a multiplicity of infection of $\sim 1$ in serum-free DMEM (with insulin-transferrin-selenium supplement and $0.2 \%$ (wt $/ \mathrm{vol}$.) BSA) and $8 \mu \mathrm{g} / \mathrm{ml}$ protamine sulphate. Plates were centrifuged for $2 \mathrm{~h}$ at $1,500 \mathrm{~g}$ and $30^{\circ} \mathrm{C}$, then cultured overnight at $32^{\circ} \mathrm{C}$. Medium was changed to complete DMEM and expression was monitored at least $72 \mathrm{~h}$ post-infection. After infection with lentivirus, cells have stable integration of the transgene(s), allowing long-term monitoring of reporter gene expression [26]. Infection efficiency ranged from $40 \%$ to $80 \%$. However, populations of infected MIN6 cells with a particular infection efficiency were used for an individual biological replicate (i.e. treated with activin A or non-treated control) and results were always normalised to the control within the same labelled population of cells, thereby controlling for differences in infection efficiency between preparations.

Screening and factorial design of experiments JMP 7.0.2 software (SAS Institute, Cary, NC, USA) was used to design two-level (i.e. zero dose and factor added) fractional factorial experiments to screen the effects of factors on $P d x 1$ and $I n s 1$ promoter activities. Initially, 12 factors were chosen at concentrations based on previous reports or preliminary single factor experiments (data not shown; ESM 
Table 1). We then chose eight factors for the second screen. The factorial design is presented in ESM Tables 2 and 3. The day before treatment, labelled MIN6 cells were seeded at 10,000 cells/well (ViewPlate-96; Perkin Elmer, Waltham, MA, USA) as a heterogeneous unsorted population of cells containing $\mathrm{Pdx}^{+} / \mathrm{Ins}^{\text {low }}$ immature cells, $\mathrm{Pdx} 1^{+} / \mathrm{Ins}^{+}$mature cells and cells that were not labelled (i.e. negative for both reporters). Cells were washed with basal medium (DMEM containing $5.5 \mathrm{mmol} / \mathrm{l}$ glucose, $0.2 \%$ (wt/vol.) BSA, $4 \mathrm{mmol} / 1$ glutamine, $100 \mathrm{U} / \mathrm{ml}$ penicillin and $172 \mu \mathrm{mol} / 1$ streptomycin) and factors were added to basal medium at concentrations and combinations described in ESM Tables 1, 2 and 3. After $48 \mathrm{~h}$ of culture, the nuclear stain Hoechst $33342(0.32 \mu \mathrm{mol} / \mathrm{l}$; Invitrogen) was added $30 \mathrm{~min}$ prior to automated imaging using a high-content screening instrument (ArrayScan VTI; Cellomics, Pittsburgh, PA, USA). Hoechst-positive, GFP-positive and RFP-positive cells were identified using fluorescence intensity cut-offs and then automatically counted (Target Activation Bioapplication; Cellomics). Cell count and intensity results for each factorial run were analysed by JMP 7.0.2 statistical software to identify the significant effects within each experiment. This analysis included analysis of multiple internal replicates for each factor in various combinations. Graphs are presented as per cent effect of each factor on the given read-out relative to no factors added (i.e. basal medium).

Flow cytometry and cell sorting For FACS analysis and sorting, stably infected MIN6 cells were lifted off plates using trypsin-EDTA, resuspended in PBS containing 5\% vol./vol. FBS and kept on ice. The influx sorter (BD Biosciences, San Jose, CA, USA) used was equipped with a tunable laser at $488 \mathrm{~nm}$ with filters $488 \mathrm{LP}$ and 531/40 for GFP, and a solid-state laser at $561 \mathrm{~nm}$ with filters $568 \mathrm{LP}$ and $624 / 40$ for RFP. Pdx $1^{+} / \mathrm{Ins}^{\text {low }}$ and $\mathrm{Pdx}^{+} / \mathrm{Ins}^{+}$cells were simultaneously sorted into chilled medium before seeding and treatment with activin A. Analysis and sorting gates are shown in a sample FACS dot plot in ESM Fig. 2.

Quantitative real-time $R T-P C R$ Total RNA was purified using a kit (RNeasy; Qiagen, Mississauga, ON, USA) and used to prepare cDNA using SuperScript III First-Strand Synthesis SuperMix for quantitative RT-PCR (Invitrogen). Primers were designed to flank an intron and are listed in ESM Table 4. Quantitative RT-PCR was performed using SYBR GreenER qPCR SuperMix (Invitrogen) and 7500 Real-Time PCR System (Applied Biosystems, Foster City, CA, USA). For relative quantification of transcripts, cycle threshold values for each sample were normalised to Gapdh.

BrdU labelling MIN6 cells were cultured for $48 \mathrm{~h}$ on 96well microplates (ViewPlate-96; Perkin Elmer) with and without activin A in basal DMEM medium, after which $10 \mu \mathrm{mol} / 1 \mathrm{BrdU}$ (Kit I; Roche Applied Science, Laval, QC, Canada) was added for $30 \mathrm{~min}$ prior to fixation and staining. Cells were imaged using an inverted microscope (Axiovert $200 \mathrm{M}$ ) equipped with a FLUAR $20 \times$ objective (Carl Zeiss, Thornwood, NY, USA). Images were analysed and quantified using a software package (SlideBook; Intelligent Imaging Innovations, Boulder, CO, USA). A minimum of 500 cells per sample were imaged and quantified.

Hormone secretion For static incubation, cells in 24-well plates were washed once and incubated for $1 \mathrm{~h}$ at $37^{\circ} \mathrm{C}$ in $3 \mathrm{mmol} / \mathrm{l}$ glucose Kreb's buffer, which was then replaced for $2 \mathrm{~h}$ with $3 \mathrm{mmol} / \mathrm{l}$ glucose, $20 \mathrm{mmol} / 1$ glucose or $30 \mathrm{mmol} / \mathrm{K} \mathrm{KCl} \mathrm{Kreb's} \mathrm{buffer} \mathrm{at} 37^{\circ} \mathrm{C}$. Buffer samples were analysed for insulin. Secreted insulin was measured using RIA (Linco/Millipore, Billerica, MA, USA). Secreted activin A was quantified using an immunoassay (Human/ Mouse/Rat Activin A; R\&D Systems).

Data analysis Data are presented as means \pm SEM. Differences between means were evaluated by Student's paired or unpaired $t$ tests, as appropriate. A $p$ value of 0.05 or less was considered significant. A minimum of three independent experiments was performed, as noted.

\section{Results}

Screening for factors that modulate adult beta cell maturity Two-level factorial designs were used to screen for significant single and interaction effects. Multiple growth factors and culture medium supplements were selected on the basis of previous reports of their mitogenic, differentiating or survival effects on pancreatic cells (ESM Table 1). The maturation state of MIN6 cells was monitored using the dual reporter $P d x l \mathrm{mRFP}-I n s l$ eGFP lentivirus described by us previously [1] in the presence of chosen factors. Changes to mature $\mathrm{Pdx} 1^{+} / \mathrm{Ins}^{+}$cells (Fig. 1a) and immature $\mathrm{Pdx} 1^{+} / \mathrm{Ins}^{\text {low }}$ cells (Fig. 1b) are shown relative to the negative control (i.e. no factors added) from two factorial experiments. All single-factor effects and only significant interaction effects are shown. After the first screen, factors that had no significant effect or had significant negative effects on one cell type (without yielding a positive effect on the other, e.g. FBS and retinoic acid) were not considered for the second screen. For both screens, $10 \mathrm{mmol} / \mathrm{l}$ glucose alone had a strong positive effect on the relative number of immature and mature MIN6 cells. This effect was probably due to increases in total cell number (data not shown). Similarly, $10 \mathrm{mmol} /$ 
a

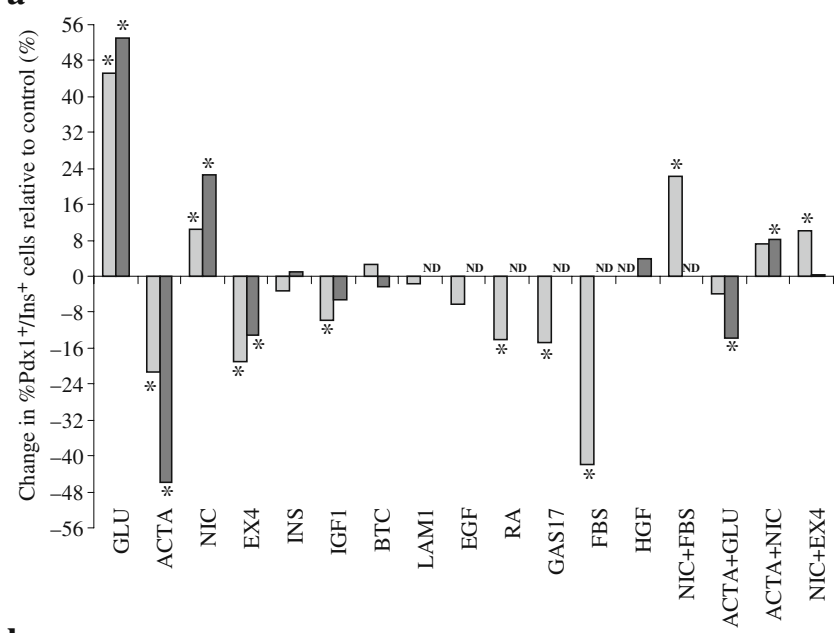

b

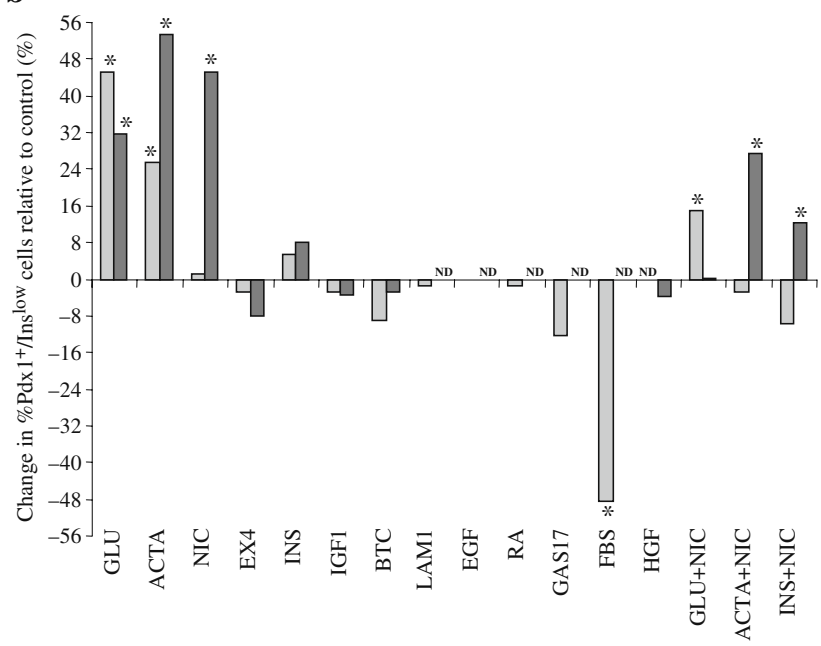

Fig. 1 Screening for factors that modulate adult beta cell maturation. Factorial design of experiments was used to screen for effects of various factors on $P d x I$ and Ins 1 promoter activity, and maturation state of dual labelled MIN6 cells. Graphs are shown for effects on $\% \mathrm{Pdx} 1^{+} / \mathrm{Ins}^{+}$ mature cells (a) and $\% \mathrm{Pdx} 1^{+} / \mathrm{Ins}^{\text {low }}$ immature cells (b) relative to control (no factors). Results are shown for two independent factorial runs (factorial 1, light grey bars; factorial 2, dark grey bars). Statistical tests for significant effects were assessed within each experiment, inherently by way of several internal replicates of each factor in various combinations, using statistical software. Similar results were obtained when the graphs were represented using a read-out of $\mathrm{Pdx} 1^{+} / \mathrm{Ins}^{\text {low }}$ and $\mathrm{Pdx}^{+} / \mathrm{Ins}^{+}$cell counts rather than the per cent changes (data not shown). ${ }^{*} p<0.05$. ND, not done. Factors: GLU, glucose; ACTA, activin A; NIC, nicotinamide; EX4, exendin 4; INS, insulin; BTC, betacellulin; LAM1, laminin 1; EGF, epidermal growth factor; RA, retinoic acid; GAS17, gastrin-17; FBS, fetal bovine serum; HGF, hepatocyte growth factor

1 nicotinamide had a positive effect on both maturation states in our second screen, but only increased the mature beta cell numbers in our first screen. Exendin-4 had a significant negative effect on the mature beta cell population in both factorial experiments.

Interestingly, activin A had a strong negative effect on mature beta cells, yet a highly significant positive effect on the relative percentage of immature beta cells (Fig. 1). Upon removal of five factors in the second screen, this opposing effect of activin A was augmented twofold. In addition, negative and positive interactions between activin A and glucose or nicotinamide, respectively, became significant in the second screen. Similar factorial design results were observed using the INS- 1 cell line labelled with the same $P d x 1 \mathrm{mRFP}-I n s 1 \mathrm{eGFP}$ dual reporter lentivirus (data not shown). Significant factor effects, as well as factor interactions, were uncovered using statistical design of experiments. For follow-up studies, we selected activin $\mathrm{A}$ as the most interesting candidate involved in modulating the maturation state of adult beta cells.

Activin A reduces beta cell maturity The effects of activin $\mathrm{A}$ on the relative numbers of immature and mature beta cells were examined using larger cultures of $P d x 1 \mathrm{mRFP}-$ Ins1eGFP dual labelled, unsorted MIN6 cells. Ins 1 promoter activity (GFP intensity) was significantly decreased by $4 \mathrm{nmol} / 1$ activin A after $72 \mathrm{~h}$ of culture (Fig. 2a). Similar results were obtained using a control single InsleGFP reporter vector, whereas activin A had no effect on the activity of a control promoter (CMVeGFP; ESM Fig. 3). $P d x 1$ promoter activity (RFP intensity) from the dual reporter vector was also decreased with activin A (data not shown). Confirming the results of the factorial screens, activin A treatment significantly increased the relative number of $\mathrm{Pdx}^{+} / \mathrm{Ins}^{\text {low }}$ immature cells (Fig. 2b), whereas it significantly decreased the number of $\mathrm{Pdx}^{+} / \mathrm{Ins}^{+}$mature cells (Fig. 2c). We next tested the effects of activin A on the spontaneous maturation of purified immature $\mathrm{Pdx}^{+} / \mathrm{Ins}^{\text {low }}$ cells [1]. FACS-sorted immature $\mathrm{Pdx}^{+} / \mathrm{Ins}^{\text {low }}$ MIN6 cells ( $>99 \%$ purity) were treated with activin A. This resulted in reduced Ins 1 promoter activity (GFP levels; Fig. 2d), a higher number of immature cells and fewer mature $\mathrm{Pdx}^{+} /$ $\mathrm{Ins}^{+}$cells relative to control (Fig. 2e). These results suggest that activin A decreases insulin gene promoter activity and reduces the rate of spontaneous beta cell maturation.

Activin A decreases expression of insulin and mature beta cell genes We analysed activin A-treated primary mouse islets and MIN6 cells for changes in the expression of genes associated with beta cell maturity and function. Real-time RT-PCR revealed that several key genes were differentially expressed between treated and control cells (Fig. 3). Specifically, Ins 1, Ins 2, Pdx1, Mafa and Glut2 (also known as Slc2a2) were significantly decreased in activin A-treated primary mouse islets (Fig. 3a). Mafa is an important transcription factor for insulin gene expression [27]. Similarly, Ins1, Ins2, Egfp, Pdx1, Mrfp, Mafa, Nkx6-1 and Glut2 were also downregulated by activin A treatment in MIN6 cells (Fig. 3b). Conversely, important transcription factors involved in early islet development, e.g. Mafb and 


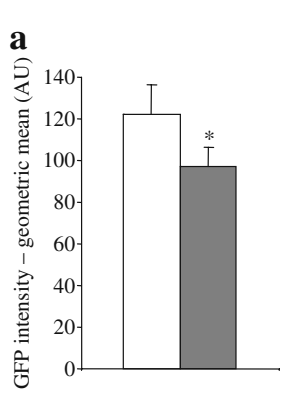

b

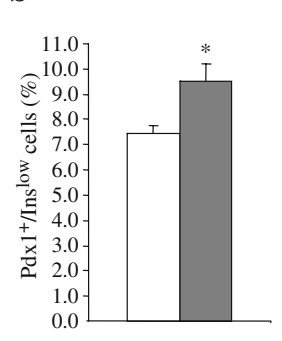

c

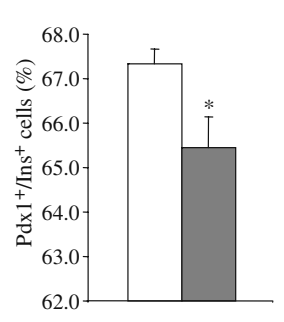

d

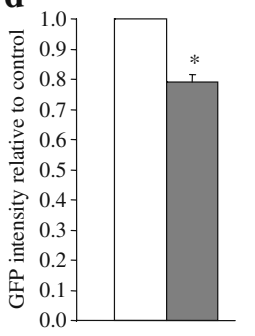

e

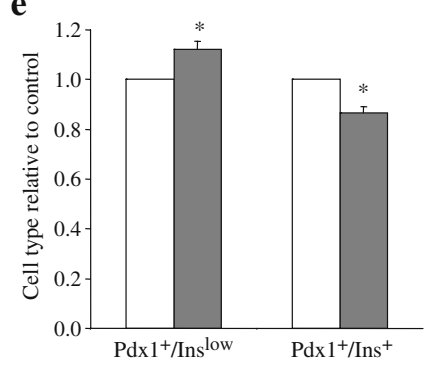

Fig. 2 Activin A decreases insulin expression and reduces maturation of immature adult beta cells. Dual labelled, unsorted MIN6 cells treated with activin A ( $4 \mathrm{nmol} / \mathrm{l}$, grey bars) for $72 \mathrm{~h}$ were analysed by FACS for (a) GFP (Insl) expression and for (b) changes in $\mathrm{Pdx}_{1}^{+}$/ Ins ${ }^{\text {low }}$ immature vs (c) $\mathrm{Pdx}^{+} / \mathrm{Ins}^{+}$mature cell numbers relative to nontreated control (white bars). AU, arbitrary units. d, e Sorted immature $\mathrm{Pdx} 1^{+} / \mathrm{Ins}^{\text {low }}$ cells were allowed to mature into $\mathrm{Pdx}^{+} / \mathrm{Ins}^{+}$cells for $72 \mathrm{~h}$ with activin A (4 nmol/l, grey bars) to assess effects on their maturation relative to non-treated control (white bars). Cells were then analysed by FACS for (d) overall GFP levels and (e) relative changes in resulting immature vs mature cell populations $(n=3){ }^{*} p<0.05$

Neurog3, tended to be increased in activin A-treated MIN6 cells (Fig. 3b) [28]. These results are similar to our previous data comparing sorted immature and mature beta cells, for instance, with opposite changes in expression of Mafa and Mafb [1]. Similar differential gene expression profiles were observed with activin A-treated human islet cells (M. Szabat, unpublished data). Together, these data strongly suggest that activin A negatively regulates adult beta cell maturity.

Activin A increases beta cell proliferation Since activin A decreases mature beta cell gene expression, we investigated whether beta cell proliferation was also increased in treated cells. Indeed, after 30 min we saw a 2.8-fold increase in $\mathrm{BrdU}$ incorporation in activin A-treated MIN6 cells (Fig. 4). Consistent with this, we observed an $11 \pm 0.5 \%$ increase in total MIN6 cell number with activin A treatment compared with controls in the factorial experiments (data not shown). We had previously shown that immature MIN6 cells proliferated faster than mature cells [1]. Taken together, these results, along with the decreased mature gene expression patterns, suggest that activin A shifts the maturation state of beta cells towards the $\mathrm{Pdx} 1^{+} / \mathrm{Ins}{ }^{\text {low }}$ immature phenotype with an increased proliferation potential. a

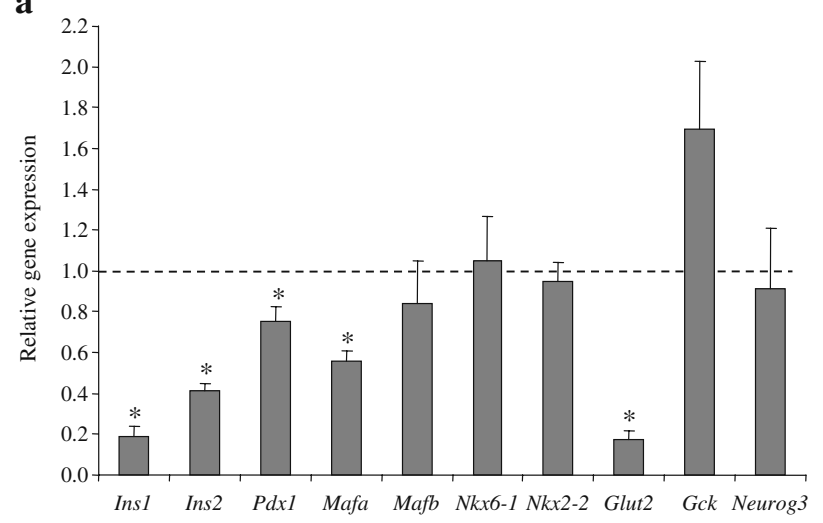

b

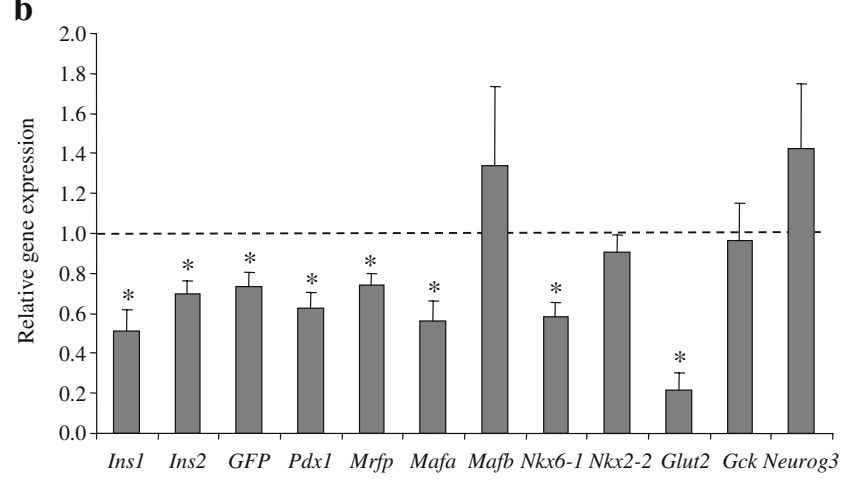

Fig. 3 Activin A decreases expression of mature beta cell genes. a Primary mouse islets $(n=4)$ and (b) dual labelled MIN6 cells $(n=8)$ were cultured with activin A ( $4 \mathrm{nmol} / \mathrm{l})$ for $72 \mathrm{~h}$ and cDNA samples were analysed by real-time RT-PCR. ${ }^{*} p<0.05$

Activin A decreases insulin secretion The large decrease in Glut2 expression along with other genes important for beta cell function in activin A-treated cells prompted us to examine the effects of activin $\mathrm{A}$ on insulin secretion. Activin A significantly decreased insulin secretion in primary mouse islets (Fig. 5a) and MIN6 cells (Fig. 5b). Insulin secretion was also $14.5 \%$ lower from activin Atreated human islets (M. Szabat, unpublished data). Since previous studies have reported that acute activin A treatment of cultured rat and human islets increased insulin secretion [21,22], we also examined the acute effects of

Fig. 4 Activin A increases beta cell proliferation. MIN6 cells were treated with activin $\mathrm{A}$ (4 nmol/l, grey bar) or nontreated (white bar) for $72 \mathrm{~h}$ and $10 \mu \mathrm{mol} / \mathrm{l} \mathrm{BrdU}$ was added for 30 min prior to fixing and staining for BrdU incorporation $(n=3) .{ }^{*} p<0.05$

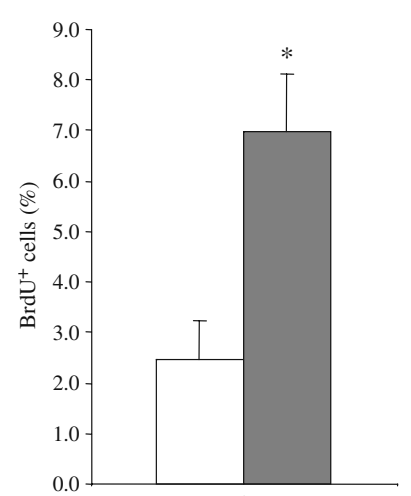



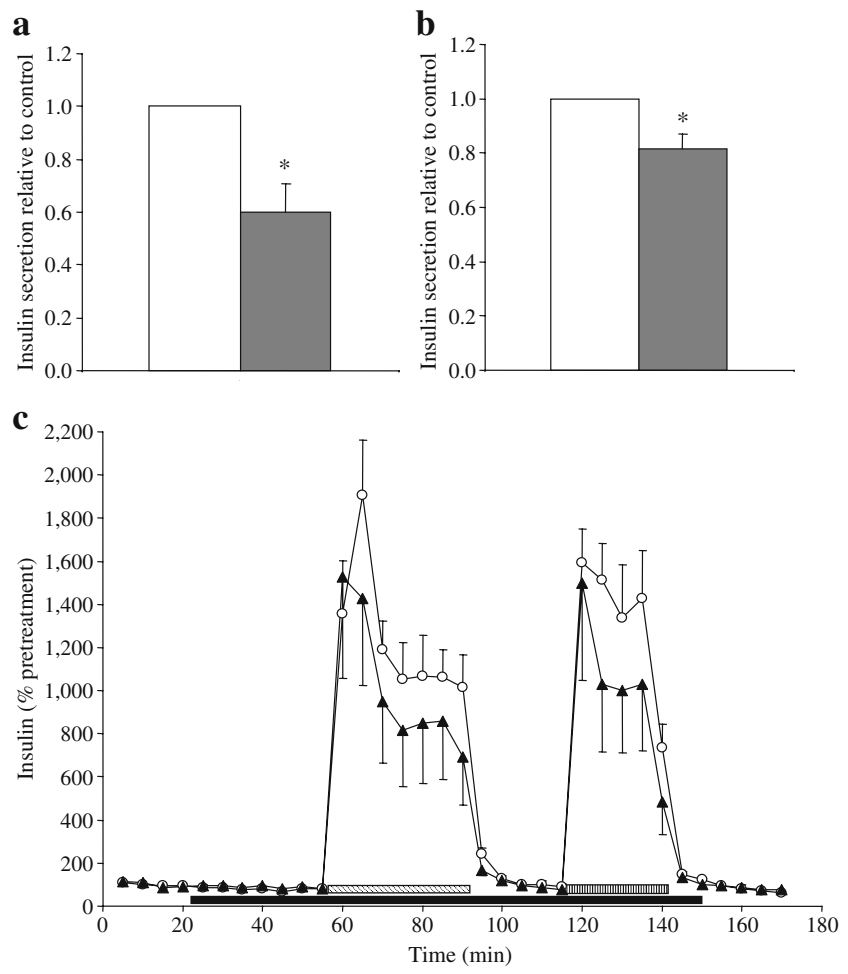

Fig. 5 Activin A decreases insulin secretion. a Primary mouse islets and (b) MIN6 cells were treated with activin A (4 nmol/l, grey bars) or non-treated (white bars) for $72 \mathrm{~h} ; n=4, * p<0.05$. c A perifusion experiment was performed using primary mouse islets to assess acute effects of activin A (4 nmol/l, black triangles) vs non-treated (white circles) on glucose-stimulated insulin secretion. Black bar, $4 \mathrm{mmol} / \mathrm{l}$ activin A; hatched bar, $20 \mathrm{mmol} / 1$ glucose; vertically hatched bar, $30 \mathrm{mmol} / \mathrm{KCl}$. $n=4$; AUC not significant

$4 \mathrm{nmol} / \mathrm{l}$ activin A in perifused mouse islets (Fig. 5c). We did not observe an increase in insulin secretion by activin $\mathrm{A}$ in the presence of $3 \mathrm{mmol} / 1$ or $20 \mathrm{mmol} / 1$ glucose, nor did we observe an increase in insulin release after depolarisation by $30 \mathrm{mmol} / \mathrm{KCl}$. In fact, we observed that activin A tended to decrease glucose-stimulated insulin secretion, although the AUC was not significantly different.

Follistatin reverses the effects of activin $A$ Pancreatic islets produce many secreted factors, which can act in an autocrine or paracrine manner. Studies have shown that mouse, rat and human pancreatic islet cells produce activin A and follistatin [23, 24, 29]. We also detected the activin $\beta$ A subunit, activin type II receptors (actRII and actRIIB) and activin type I receptor (actRIB/alk4) in human islets (data not shown). Mouse islets and MIN6 cells secreted 1 to $2 \mathrm{pmol} / \mathrm{l}$ activin A per day per 200,000 cells into the culture media (Fig. 6a). These data suggest that activin $\mathrm{A}$ is released from pancreatic islets, where it can act locally to regulate maturation state of adult beta cells.

Follistatin is a specific and potent antagonist of activin A, preventing binding to its receptor [30]. Indeed, follistatin completely reversed the effects of activin A on Ins 1 promoter activity, MIN6 maturation state, insulin gene expression and the expression of maturity-associated genes (Fig. 6). In some cases, follistatin not only reversed the effects of activin, but appeared to have significant effects of its own, suggesting the reversal of endogenous local activin signalling (Fig. 6b-e).

Since activin A decreased insulin secretion in primary mouse and human islets, and in MIN6 cells, we investigated whether follistatin could increase insulin secretion. Indeed, activin A significantly decreased, whereas follistatin increased insulin secretion from MIN6 cells over $72 \mathrm{~h}$, albeit at a $p$ value of 0.07 (Fig. 7a). Co-treatment with activin A and follistatin significantly increased insulin secretion. Furthermore, glucose and $\mathrm{KCl}$-stimulated insulin secretion was significantly
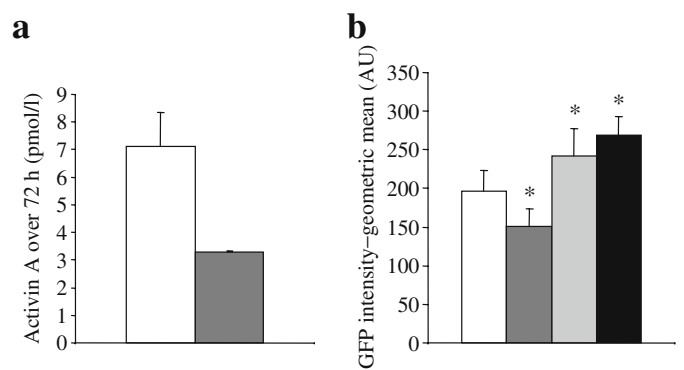

c

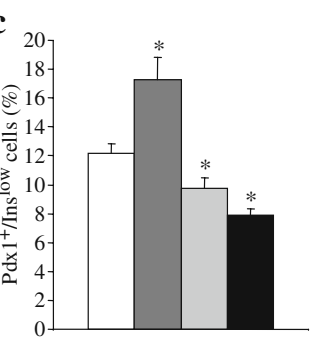

d

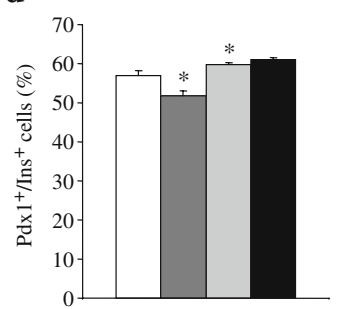

e

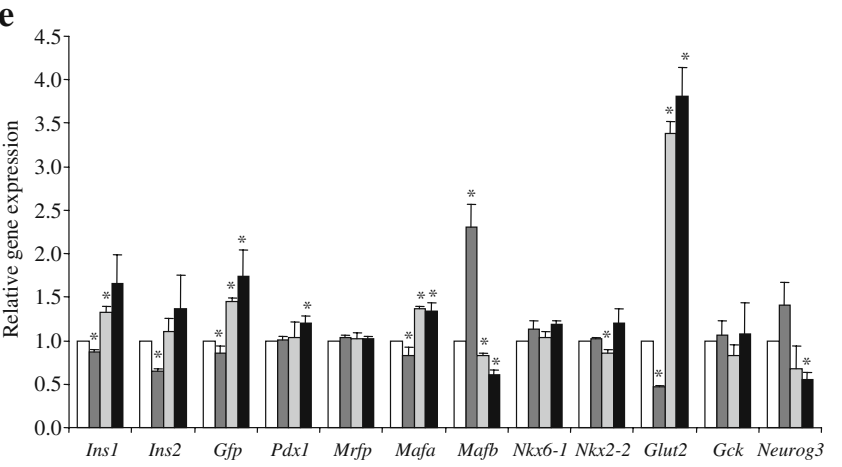

Fig. 6 Follistatin increases expression of insulin gene and other mature beta cell genes. a Rate of activin A secretion from MIN6 cells (white bar) and primary mouse islets (grey bar) was quantified. b-d Dual labelled MIN6 cells were treated for $72 \mathrm{~h}$ with activin A ( $2 \mathrm{nmol} / \mathrm{l}$, dark grey bars), follistatin (100 nmol/l, light grey bars), both (black bars) or non-treated (white bars) and analysed by FACS for (b) GFP (Ins I) expression and for changes in (c) immature $\mathrm{Pdx} 1^{+} / \mathrm{Ins}^{\text {low }}$ vs (d) mature $\mathrm{Pdx}^{+} / \mathrm{Ins}^{+}$cell numbers. e cDNA samples were analysed for changes in gene expression by real-time RT-PCR; $n=3,{ }^{*} p<0.05$ 


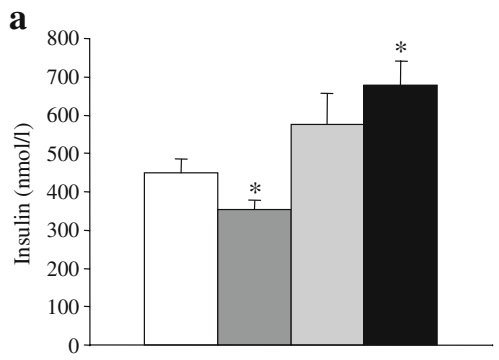

b
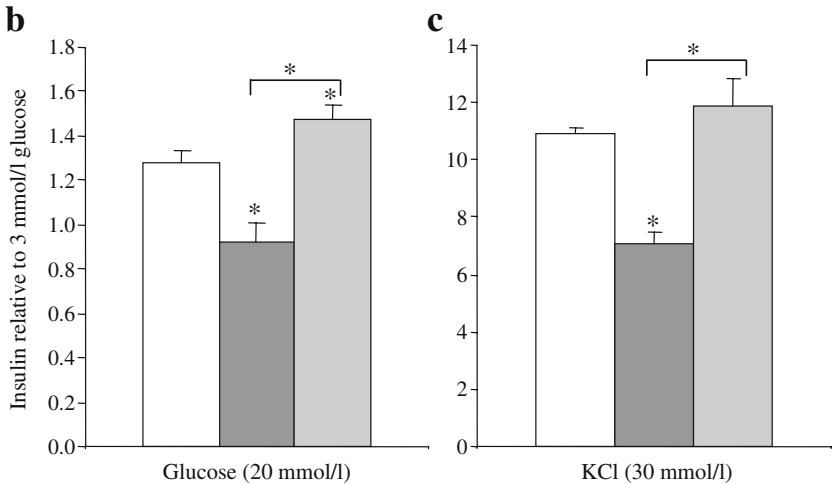

Fig. 7 Follistatin reverses the effects of activin A on insulin secretion. MIN6 cells were cultured for $72 \mathrm{~h}$ with activin A ( $2 \mathrm{nmol} / \mathrm{l}$, dark grey bars), follistatin (100 nmol/l, light grey bars), both (black bars) or nontreated (white bars). a Media samples with accumulated insulin over $72 \mathrm{~h}(n=4)$. b Static incubation buffer samples $(n=3)$ were analysed for insulin at $20 \mathrm{mmol} / 1$ glucose and at (c) $30 \mathrm{mmol} / 1 \mathrm{KCl}{ }^{*} p<0.05$

reduced by activin A and increased by follistatin in MIN6 cells (Fig. 7b, c). Collectively, these results suggest that activin A dedifferentiates adult beta cells, and follistatin blocks this effect and enhances beta cell maturation.

\section{Discussion}

The present study sought to identify factors that modulate adult beta cell maturity. Using dual labelled MIN6 cells [1], candidate factors were systematically screened for their effects on $P d x I$ and Ins 1 promoter activities. The major finding of our study was that activin A and follistatin had powerful reciprocal effects on beta cell maturity. These results contribute to the understanding of maturation and plasticity in adult beta cells.

Factorial design offers insight into the complexity of interaction of various in vitro culture conditions, factors and nutrients, while substantially decreasing the number of experiments required [31]. For example, our fractional factorial design for factorial 1 required $2^{12-6}=64$, instead of $2^{12}=4,096$ individual treatments, if all combinations of 12 factors were screened. Thus, the statistical design of experiments, which is used much more frequently in engineering science, can be a valuable tool in screening experiments designed to elucidate important interaction effects $[6,32]$. The factorial design method revealed a number of interesting effects on adult beta cell maturity. For example, high glucose had highly significant positive effects on the relative numbers of immature and mature beta cells. Nicotinamide is generally used in cell culture media as a vitamin supplement and has been shown to promote differentiation of pancreatic fetal cells into insulinpositive cells [8]. In our screens, nicotinamide also had positive effects. While synergistic or negative interaction effects can be masked in conventional screening experiments, our statistical design uncovered hidden interactions of factors including synergy between nicotinamide and high glucose, FBS or exendin-4. However, upon removal of many negative or insignificant first screen factors (such as FBS, IGF-1, retinoic acid and gastrin17) from the second screen, these synergies were lost, but new synergies between nicotinamide and activin A or insulin were uncovered. While previous studies have generally shown beneficial effects of exendin- 4 on beta cell function and survival $[33,34]$, we observed a significant negative effect of exendin- 4 on beta cell maturity.

Emerging evidence of pancreatic tissue plasticity suggests that normally quiescent, terminally differentiated pancreatic cells retain the potential to dedifferentiate, transdifferentiate or increase their proliferation after specific molecular cues in vitro and in vivo [3-5, 35]. Our findings support the notion that beta cell plasticity can be modified by external molecular cues. Activin A decreased Ins I promoter activity, downregulated expression of several mature beta cell genes, increased proliferation and dampened insulin secretion in primary islets and MIN6 cells. Conversely, follistatin completely reversed the dedifferentiating effects of activin A. Both activin A and follistatin are produced in islets $[23,24]$, suggesting paracrine control of beta cell maturity. Interestingly, a preliminary experiment showed that levels of the activin $\beta$ A subunit were increased in human islets treated with activin A (M. Szabat, unpublished data), supporting a positive feedback for autocrine or paracrine regulation of activin A expression.

The mature beta cell phenotype is commonly defined by the expression of genes such as the insulin gene, $P d x l$, Glut2, Mafa, Neurod1, glucokinase and Nkx6-1 [36]. In our activin A-treated cells, genes associated with beta cell maturity, specifically Ins 1, Ins 2, Pdx1, Glut2, Nkx6-1 and $M a f a$ were downregulated. Follistatin increased the expression of these genes. Consistent with these negative effects of activin $\mathrm{A}$, the TGF $\beta / \mathrm{SMAD}$ pathway is known to restrict pancreatic progenitor specification, in part by restraining $P d x 1$ expression during early embryonic development [37]. The notion that activin $\mathrm{A}$ is a tonic negative regulator of beta cell differentiation and function in the adult islet is supported by a recent study showing that TGF $\beta /$ SMAD3 signalling repressed insulin gene and other mature beta cell 
genes and also that downregulation of Smad 3 improved beta cell function [38]. Bone morphogenetic protein (BMP) signalling, also mediated via SMADs, prevented beta cell differentiation in zebrafish [39]. Thus, both the TGF $\beta$ and BMP superfamilies appear to have suppressive roles in adult beta cell maturation.

Activin A increased expression of Mafb and decreased that of Mafa in MIN6 cells, whereas follistatin had the opposite effect. This pattern of Mafa and Mafb expression in activin A-treated cells is consistent with a dedifferentiated, immature beta cell phenotype, as it occurs during endocrine development. In murine pancreas development, $M a f b$ is expressed before Mafa, followed by Mafb downregulation in adult beta cells [40]. Mafb is required for beta cell maturation and directly regulates expression of Mafa, $P d x 1, N k x 6-1$, Glut2 and insulin [28]. Activin A did not increase Mafb expression in primary mouse islet cells, as it did in MIN6, probably because islet alpha cells express high levels of Mafb [41] and a small increase in beta cell Mafb expression with activin A treatment might not have been detectable above control.

We previously found that neurogenin 3 (NEUROG3) message and protein are present in adult human islets, mouse islets and MIN6 cells, where they are regulated by notch signalling [42]. Subsequently, the presence of NEUROG3 protein has been confirmed by others and its role in the maintenance of adult beta cell maturity was suggested [43]. It is possible that activin and follistatin have reciprocal effects on NEUROG3 levels in beta cells, but it remains to be determined whether NEUROG3 mediates the effects of activin or follistatin on key beta cell genes such as Mafa and Glut2.

GLUT2 is required for glucose sensing, normal glucose homeostasis and insulin secretion [44]. Glut2 was one of the most highly regulated candidate genes in activin A- or follistatin-treated islets and MIN6 cells. Similarly, Glut2 was significantly decreased in $\mathrm{Pdx} 1^{+} / \mathrm{Ins}^{\text {low }}$ immature beta cells [1]. Consistent with our findings, Glut2 was elevated in Smad3 knockout islets [38]. A strong reduction in Glut2 expression is an early indicator of beta cell stress and possibly dedifferentiation in many mouse models of glucose intolerance or diabetes [45], including mice with reduced $P d x 1$ [46]. It will be interesting in the future to examine the characteristics and plasticity of the population of adult pancreatic cells with low Glut2 expression.

Our proliferation results with MIN6 cells are also consistent with another study that showed an approximately threefold increase in proliferation of primary rat beta cells treated with activin A [47]. Collectively, activin A and follistatin appear to modulate the maturation state of adult beta cells, with activin A driving mature beta cells to a more progenitor-like phenotype with increased proliferation and decreased differentiated function.
Reports on activin A effects on insulin secretion are conflicting. Acute activin A treatment of cultured rat and human islets was reported to increase insulin secretion [21, 22]; however acutely treated MIN6 cells did not show increased secretion [29]. In our study, activin A had no acute stimulatory effect on glucose-stimulated insulin secretion in perifused isolated mouse islets, while prolonged activin A treatment significantly decreased insulin secretion. It is possible that any acute activin A effects on insulin secretion may be mediated through a SMAD-independent, nontranscriptional signalling mechanism [48].

In addition to its effects on beta cell function, activin A has been reported to be a differentiation factor. In vitro, it appeared to direct pancreatic fetal cells into insulin-positive cells [17]. Although activin A maintains pluripotency and self-renewal of embryonic stem cells [49], it is also required to induce stem cell differentiation into insulin-positive cells [50]. Our results support a dedifferentiating role for activin A in adult beta cells. In this regard, activin A receptors, activin type I receptor and activin type II B receptor, were found to be expressed at a higher level in adult vs neonatal beta cells (S. Bonner-Weir, Harvard, Boston, MA, USA; personal communication), supporting a differential role for activin signalling at different stages of beta cell development.

In summary, our results demonstrate that local factors, such as activin and follistatin, control the maturation status of adult beta cells. Identification of modulators of beta cell replication and maturation will help in the development of therapies designed to increase functional beta cell mass in vivo, as well as helping to find alternative sources of transplantable beta cells in vitro.

Acknowledgements We thank T. Kieffer and R. Kay for advice and reagents, C. Hoesli and D. Luciani for advice, L. Marmolejo and X. $\mathrm{Hu}$ for technical assistance, and $\mathrm{G}$. Warnock for human islets. Research was supported by operating grants to J .D. Johnson and J. M. Piret from the Stem Cell Network, the Juvenile Diabetes Research Foundation (JDRF) and the Canadian Institutes of Health Research (CIHR). Infrastructure support of the Michael Smith Foundation for Health Research (MSFHR)-funded Centre for Human Islet Transplantation and Beta-Cell Regeneration is acknowledged. J. D. Johnson was supported by salary awards from MSFHR, CIHR, JDRF and the CDA. M. Szabat was supported by studentships from NSERC, MSFHR, CIHR and the University of British Columbia.

Duality of interest The authors declare that there is no duality of interest associated with this manuscript.

\section{References}

1. Szabat M, Luciani DS, Piret JM, Johnson JD (2009) Maturation of adult beta-cells revealed using a Pdx1/insulin dual-reporter lentivirus. Endocrinology 150:1627-1635

2. Sachdeva MM, Stoffers DA (2009) Minireview: meeting the demand for insulin: molecular mechanisms of adaptive postnatal beta-cell mass expansion. Mol Endocrinol 23:747-758 
3. Zhou Q, Brown J, Kanarek A, Rajagopal J, Melton DA (2008) In vivo reprogramming of adult pancreatic exocrine cells to betacells. Nature 455:627-632

4. Russ HA, Ravassard P, Kerr-Conte J, Pattou F, Efrat S (2009) Epithelial-mesenchymal transition in cells expanded in vitro from lineage-traced adult human pancreatic beta cells. PLoS One 4: e6417

5. Nir T, Melton DA, Dor Y (2007) Recovery from diabetes in mice by beta cell regeneration. J Clin Invest 117:2553-2561

6. Audet J, Miller CL, Eaves CJ, Piret JM (2002) Common and distinct features of cytokine effects on hematopoietic stem and progenitor cells revealed by dose-response surface analysis. Biotechnol Bioeng 80:393-404

7. Rafiq I, da Silva XG, Hooper S, Rutter GA (2000) Glucosestimulated preproinsulin gene expression and nuclear translocation of pancreatic duodenum homeobox-1 require activation of phosphatidylinositol 3-kinase but not p38 MAPK/SAPK2. J Biol Chem 275:15977-15984

8. Otonkoski T, Beattie GM, Mally MI, Ricordi C, Hayek A (1993) Nicotinamide is a potent inducer of endocrine differentiation in cultured human fetal pancreatic cells. J Clin Invest 92:1459-1466

9. Movassat J, Beattie GM, Lopez AD, Hayek A (2002) Exendin 4 up-regulates expression of PDX 1 and hastens differentiation and maturation of human fetal pancreatic cells. J Clin Endocrinol Metab 87:4775-4781

10. Beith JL, Alejandro EU, Johnson JD (2008) Insulin stimulates primary beta-cell proliferation via Raf-1 kinase. Endocrinology 149:2251-2260

11. Johnson JD, Bernal-Mizrachi E, Alejandro EU et al (2006) Insulin protects islets from apoptosis via Pdx1 and specific changes in the human islet proteome. Proc Natl Acad Sci U S A 103:1957519580

12. Huotari MA, Palgi J, Otonkoski T (1998) Growth factor-mediated proliferation and differentiation of insulin-producing INS-1 and RINm5F cells: identification of betacellulin as a novel beta-cell mitogen. Endocrinology 139:1494-1499

13. Jiang FX, Cram DS, DeAizpurua HJ, Harrison LC (1999) Laminin-1 promotes differentiation of fetal mouse pancreatic beta-cells. Diabetes 48:722-730

14. Suarez-Pinzon WL, Yan Y, Power R, Brand SJ, Rabinovitch A (2005) Combination therapy with epidermal growth factor and gastrin increases beta-cell mass and reverses hyperglycemia in diabetic NOD mice. Diabetes 54:2596-2601

15. Micallef SJ, Janes ME, Knezevic K, Davis RP, Elefanty AG, Stanley EG (2005) Retinoic acid induces Pdx1-positive endoderm in differentiating mouse embryonic stem cells. Diabetes 54:301305

16. Zhan XR, Li XY, Liu XM et al (2009) Generation of insulinsecreting cells from adult rat pancreatic ductal epithelial cells induced by hepatocyte growth factor and betacellulin-delta4. Biochem Biophys Res Commun 382:375-380

17. Demeterco C, Beattie GM, Dib SA, Lopez AD, Hayek A (2000) A role for activin $\mathrm{A}$ and betacellulin in human fetal pancreatic cell differentiation and growth. J Clin Endocrinol Metab 85:3892-3897

18. Tsuchida K, Nakatani M, Hitachi K et al (2009) Activin signaling as an emerging target for therapeutic interventions. Cell Commun Signal 7:15-25

19. Kim SK, Hebrok M, Li E et al (2000) Activin receptor patterning of foregut organogenesis. Genes Dev 14:1866-1871

20. Zhang YQ, Cleary MM, Si Y et al (2004) Inhibition of activin signaling induces pancreatic epithelial cell expansion and diminishes terminal differentiation of pancreatic beta-cells. Diabetes 53:2024-2033

21. Totsuka Y, Tabuchi M, Kojima I, Shibai H, Ogata E (1988) A novel action of activin A: stimulation of insulin secretion in rat pancreatic islets. Biochem Biophys Res Commun 156:335-339
22. Florio P, Luisi S, Marchetti P et al (2000) Activin A stimulates insulin secretion in cultured human pancreatic islets. J Endocrinol Invest 23:231-234

23. Wada M, Shintani Y, Kosaka M, Sano T, Hizawa K, Saito S (1996) Immunohistochemical localization of activin A and follistatin in human tissues. Endocr J 43:375-385

24. Ogawa K, Abe K, Kurosawa N et al (1993) Expression of alpha, beta $A$ and beta $B$ subunits of inhibin or activin and follistatin in rat pancreatic islets. FEBS Lett 319:217-220

25. Johnson JD, Ford EL, Bernal-Mizrachi E et al (2006) Suppressed insulin signaling and increased apoptosis in CD38-null islets. Diabetes 55:2737-2746

26. Cockrell AS, Kafri T (2007) Gene delivery by lentivirus vectors. Mol Biotechnol 36:184-204

27. Olbrot M, Rud J, Moss LG, Sharma A (2002) Identification of beta-cell-specific insulin gene transcription factor RIPE3b1 as mammalian MafA. Proc Natl Acad Sci U S A 99:6737-6742

28. Artner I, Blanchi B, Raum JC et al (2007) MafB is required for islet beta cell maturation. Proc Natl Acad Sci U S A 104:38533858

29. Tsuchida K, Nakatani M, Yamakawa N, Hashimoto O, Hasegawa Y, Sugino H (2004) Activin isoforms signal through type I receptor serine/threonine kinase ALK7. Mol Cell Endocrinol 220:59-65

30. Nakamura T, Takio K, Eto Y, Shibai H, Titani K, Sugino H (1990) Activin-binding protein from rat ovary is follistatin. Science 247:836-838

31. Montgomery DC (2001) Design and analysis of experiments. Wiley, New York

32. Titmarsh D, Cooper-White J (2009) Microbioreactor array for fullfactorial analysis of provision of multiple soluble factors in cellular microenvironments. Biotechnol Bioeng 104:1240-1244

33. Johnson JD, Ao Z, Ao P et al (2009) Different effects of FK506, rapamycin, and mycophenolate mofetil on glucose-stimulated insulin release and apoptosis in human islets. Cell Transplant $18: 833-845$

34. Drucker DJ (2005) Biologic actions and therapeutic potential of the proglucagon-derived peptides. Nat Clin Pract Endocrinol Metab 1:22-31

35. Inada A, Nienaber C, Katsuta $\mathrm{H}$ et al (2008) Carbonic anhydrase II-positive pancreatic cells are progenitors for both endocrine and exocrine pancreas after birth. Proc Natl Acad Sci U S A 105:19915-19919

36. Bernardo AS, Hay CW, Docherty K (2008) Pancreatic transcription factors and their role in the birth, life and survival of the pancreatic beta cell. Mol Cell Endocrinol 294:1-9

37. Wandzioch E, Zaret KS (2009) Dynamic signaling network for the specification of embryonic pancreas and liver progenitors. Science 324:1707-1710

38. Lin HM, Lee JH, Yadav H et al (2009) Transforming growth factor-beta/Smad3 signaling regulates insulin gene transcription and pancreatic islet beta-cell function. J Biol Chem 284:1224612257

39. Chung WS, Andersson O, Row R, Kimelman D, Stainier DY (2010) Suppression of Alk8-mediated Bmp signaling cellautonomously induces pancreatic $\beta$-cells in zebrafish. Proc Natl Acad Sci U S A 107:1142-1147

40. Nishimura W, Kondo T, Salameh T et al (2006) A switch from MafB to MafA expression accompanies differentiation to pancreatic beta-cells. Dev Biol 293:526-539

41. Artner I, Le Lay J, Hang Y et al (2006) MafB: an activator of the glucagon gene expressed in developing islet alpha- and beta-cells. Diabetes 55:297-304

42. Dror V, Nguyen V, Walia P, Kalynyak TB, Hill JA, Johnson JD (2007) Notch signalling suppresses apoptosis in adult human and mouse pancreatic islet cells. Diabetologia 50:2504-2515 
43. Wang S, Jensen JN, Seymour PA et al (2009) Sustained Neurog3 expression in hormone-expressing islet cells is required for endocrine maturation and function. Proc Natl Acad Sci U S A 106:9715-9720

44. Guillam MT, Hummler E, Schaerer E et al (1997) Early diabetes and abnormal postnatal pancreatic islet development in mice lacking Glut-2. Nat Genet 17:327-330

45. Reimer MK, Ahren B (2002) Altered beta-cell distribution of pdx1 and GLUT-2 after a short-term challenge with a high-fat diet in C57BL/6J mice. Diabetes 51(Suppl 1):S138-S143

46. Brissova M, Shiota M, Nicholson WE et al (2002) Reduction in pancreatic transcription factor PDX-1 impairs glucose-stimulated insulin secretion. J Biol Chem 277:11225-11232
47. Brun T, Franklin I, St-Onge L et al (2004) The diabeteslinked transcription factor PAX4 promotes $\beta$-cell proliferation and survival in rat and human islets. J Cell Biol 167:11231135

48. Moustakas A, Heldin CH (2005) Non-Smad TGF-beta signals. J Cell Sci 118:3573-3584

49. Beattie GM, Lopez AD, Bucay N et al (2005) Activin A maintains pluripotency of human embryonic stem cells in the absence of feeder layers. Stem Cells 23:489-495

50. D'Amour KA, Bang AG, Eliazer S et al (2006) Production of pancreatic hormone-expressing endocrine cells from human embryonic stem cells. Nat Biotechnol 24:1392-1401 